Article

\title{
Can Weblogs and Microblogs Change Traditional Scientific Writing?
}

\section{Martin Ebner $^{1, *}$ and Hermann Maurer ${ }^{2}$}

1 Social Learning, Computer and Information Services, Graz University of Technology, Steyrergasse 30, $8010 \mathrm{Graz}$, Austria

2 Institute for Information Systems and Computer Media, Graz University of Technology, Inffeldgasse 16, 8010 Graz, Austria; E-Mail: hmaurer@iicm.edu

* Author to whom correspondence should be addressed; E-Mail: martin.ebner@tugraz.at.

Received: 22 September 2009; in revised form: 16 November 2009 / Accepted: 16 November 2009 / Published: 18 November 2009

\begin{abstract}
This paper describes a follow-up Web 2.0 approach to a technology enhanced master course for students of Graz University of Technology. The lecture "Social Aspects of Information Technology" has a long tradition for using new didactical scenarios as well as modern e-Learning technologies. After using a blogosphere one year ago, this year microblog channels helped to expand the traditional lecture. Students choose (on a voluntary basis) whether they want to participate in a blogging/microblogging group instead of using conventional methods called Scientific Writer/Scientific Reviewer. This study addresses the question whether this method can change the learning outcome into a more reflective one. Furthermore, peer-reviewing groups judge the quality of essays and blog contributions. In this paper we examine if microblogging can be an appropriate technology for assisting the process. This publication comes to the conclusion that an amazing potential and a new way to work with information is opened when using microblogging. Students seem to be more engaged, reflective and critical in as much as they presented much more personal statements and opinions than years before.
\end{abstract}

Keywords: scientific writing; blogs; Web 2.0 


\section{Introduction}

Mark Prensky [1] wrote, “Our students have changed radically. Today's students are no longer the people our educational system was designed to teach". Considering the radical changes of today often summarized as Web 2.0 or e-Learning 2.0 is there really a dramatically breakpoint? Are learners who are reaching the university not comparable to those of some years ago? Currently many such questions are discussed within the university, but only little research has been done.

While the so called Web 2.0 hype is cooling down, we see that the "Read/Write" Web is becoming a serious business. People that were skeptics once are now integrating the tools provided into their daily workflow. Thus, we can expect the technology to become more and more a part of our lives [2]. School children and teenagers in particular are very fast at adopting new habits and are likely to try out many different approaches. In the field of e-Learning additional issues play important roles: How accepted are these new technologies among people who are coming to study at our university? Do they only consume knowledge or do they contribute their own work and ideas? Do they know how to handle blogs, wikis and similar platforms? How much can they benefit from working with these? Or the other way round: how much do we impede them by not offering new ways of learning and community work?

Due to the fact that Internet pervades our daily life and its availability is still increasing, perhaps the whole teaching and learning process of the university has to be rethought. Increasingly we are living our lives on the Internet: banking activities, booking, reading news and so on, will lead to new ways of use [3]. Growing bandwidth accommodates the demand for watching TV and movies online or sending audio files as podcasts all over the world. These change our life and our behavior tremendously.

The availability of new mobile devices such as mobile phones or PDAs implies the use of them [4] not only in business or private life but also for learning scenarios [5]. Technology impacts learning environments and learning styles [6]. If people are becoming more and more mobile, why should they not learn mobile? Is this the challenge of the future? Why should we not adapt informal communication, distribution and consumption structures for learning processes?

As a matter of fact we are convinced that learning and all further processes concerning the educational system are changing. Ally [7] mentioned: „At the same time, today's and tomorrow's learners will be nomadic and continuously on the move. As learners move from one location to the next, they must be able to use the infrastructure in different locations to access learning materials. Hence, learning materials must be designed for easy access by the nomadic learners using mobile technology regardless of where they are located and which network infrastructure they are using to access information".

Obviously there are many facts pointing to a different future in learning behavior. How does this reflect in the current situation at a university? Some research work in the last years tried to identify the differences between teenagers, the so called "net generation" [8] or "digital natives" [1] and so on, and their lecturers. Some further studies $[9,10]$ pointed out that the change is not as dramatically as might be expected.

However, it must be concluded that the Web 2.0 [11] is a new expression for dealing with online information. Due to the fact that is widely used, innovative technologies lead to changes of society; it seems to be obvious that children, students or teachers will be practicing a different kind of learning 
and teaching in the future. Using Web 2.0 technologies for learning purposes, called e-Learning 2.0, was first coined by Stephen Downes [12] in 2005. One small aspect in the broad range of possibilities is the use of Weblogs. "A frequently updated website consisting of data entries arranged in reverse chronological order" $[13,14]$ is a simple definition.

This paper deals with the use of Weblogs and Microblogs during a course in computer science. We address the research question "How can Weblogs and Microblogs enhance a traditional lecture?".

\section{Weblogs - Microblog - Blogosphere}

"Every 30 seconds a new Weblog is born" - a simple slogan of the biggest weblog search engine Technorati.com (http://technorati.com). But what does it mean? How powerful are weblogs and why are so many created within a short time frame? Weblogs get more and more popular and influence the existing landscape of traditional media. According to Rosenbloom this kind of web publishing tool is becoming a new form of mainstream of personal communication [15].

From a technical point of view weblogs are a very simple tool. They are mostly programmed as php-applications and linked to a standard SQL database. Anyone (called Blogger) can write contributions via a WYSWYG-editor and publish them to the Internet by saving. Thus, becoming an active part of the Internet [16], by using a user-centered, decentralized concept [17], a so-called peruser publication form [17], gets much more powerful than was expected in the beginning. RSS (Really Simple Syndication) feeds helped to disperse information rapidly. By subscribing to a feed, information is not found by active searching but rather automatically provided. The sum of all Weblogs is called the Blogosphere.

The usage of weblog seems to be well established and first researchers show impressive results [19-22]. Weblogs are mainly used for writing short essays and thoughts. Contributions are more or less commented by readers, sometimes small discussions are started. Although blogging is an appropriate form to write fast and small contributions on the web, there is a need to publish sometimes even faster. For example you are on the move and see something interesting (picture, link, etc.) or you read an interesting article and like to share it. In this case a blog contribution is too complicated - this leads to a new form of blogging, called microblogging. Posting updates, ideas or simple notifications [23] is the power of microblog platforms like Twitter, Tumblr and Plurk. Java [24] claimed three types of microblogging: information sharing, information seeking and friendship-wise relationship. Ebner \& Schiefner [25] expanded these types of microblogging by expressing the communication aspect. Especially learning is an active process on the part of the learner [26] and proceeds through conversation.

The research question we like to address is to investigate how weblogs as well as microblogs can be used to enhance traditional lectures in Higher Education.

\section{The Study}

In October 2006 Graz University of Technology has launched an own blogosphere for all university members - students as well as lecturers. The environment is called TU Graz LearnLand (http://tugll.tugraz.at) and is comparable to blogger.com. Every logged-in-user has his/her own weblog with the possibility to write, collaborate and share contents [27]. Further, the system allows creating 
special communities. Each community has also an own weblog, which can be actively used by its specified members. In other words TU Graz LearnLand consists of a number of personal and community weblogs.

To investigate the use of weblogs and microblogs, the microblogging application Jaiku (http://jaiku.com) has been chosen. Similar to Twitter (http://twitter.com) small messages up to 140 characters can be posted to the personal microblog, a so-called channel. A channel is similar to a community weblog.

As an example the course "Social Aspects of Information Technology" was chosen. This course is an obligatory one for students of informatics during their bachelor program and tries to educate students to have a critical view on how informatics influences the human society of today. More than 200 students attend this course every year to listen to about 17 presentations held by different experts in different fields. Topics are for example Human Computer Interaction, eHealth, Google, Weblogs as well as Virtual Worlds or the use of informatics in civil engineering.

In recent years, students had to write two essays on topics of their own choice to pass the lecture. Based on the strict scientific rules a high amount of text documents have been composed. The big drawback of this method is that except for teachers, nobody else is reading any text of the students. From a very critical point of view it can be argued that the presentations of the experts was concentrated into a written form by the students. Nearly no reflection and discussion about the topics occurs during the whole lecture. Hence a new didactical concept was needed to increase students' activity.

Three crucial didactical factors must be considered:

1. Reflection: Students have to rethink the presentation of the experts and form their very own opinion. Critical thinking and awareness about technology impacts and effects is the target of the lecture.

2. Discussion: Due to the fact that discussions lead to more than one perspective on a specific topic, these enhance the visible spectrum for each learner.

3. Quality: The major critics concerning the content of subjective user-driven essays concern a lack of scientific quality. Hence it must be ensured that arguments and opinions are strongly based on usual scientific rules, methods and approaches.

\section{Didactical Concept}

To ensure the three crucial factors as defined in above (reflection, discussion and quality) students were able to choose one of the following four groups:

1. Scientific Writer: Students attending this group have to write two short essays about topics of their own choice. In a very traditional way text documents were provided at a specific deadline to the learning platform.

2. Scientific Reviewer: Similar to reviewers of publications, these students take the essays of the Writer Group and review them. Each student has to review at least 4 documents. So each essay has at least 2 reviews. 
3. Blogger: The blogging group handles a community weblog to the lectures' topics. Providing at least two weblog-posts a week is the main task of these learners.

4. Microblogger: The last group is about Microblogging. Students attending this group have to post at least two microblogs each week and further comment at least two blog posts of the blogger group.

Figure 1. Overview of the didactical concept.

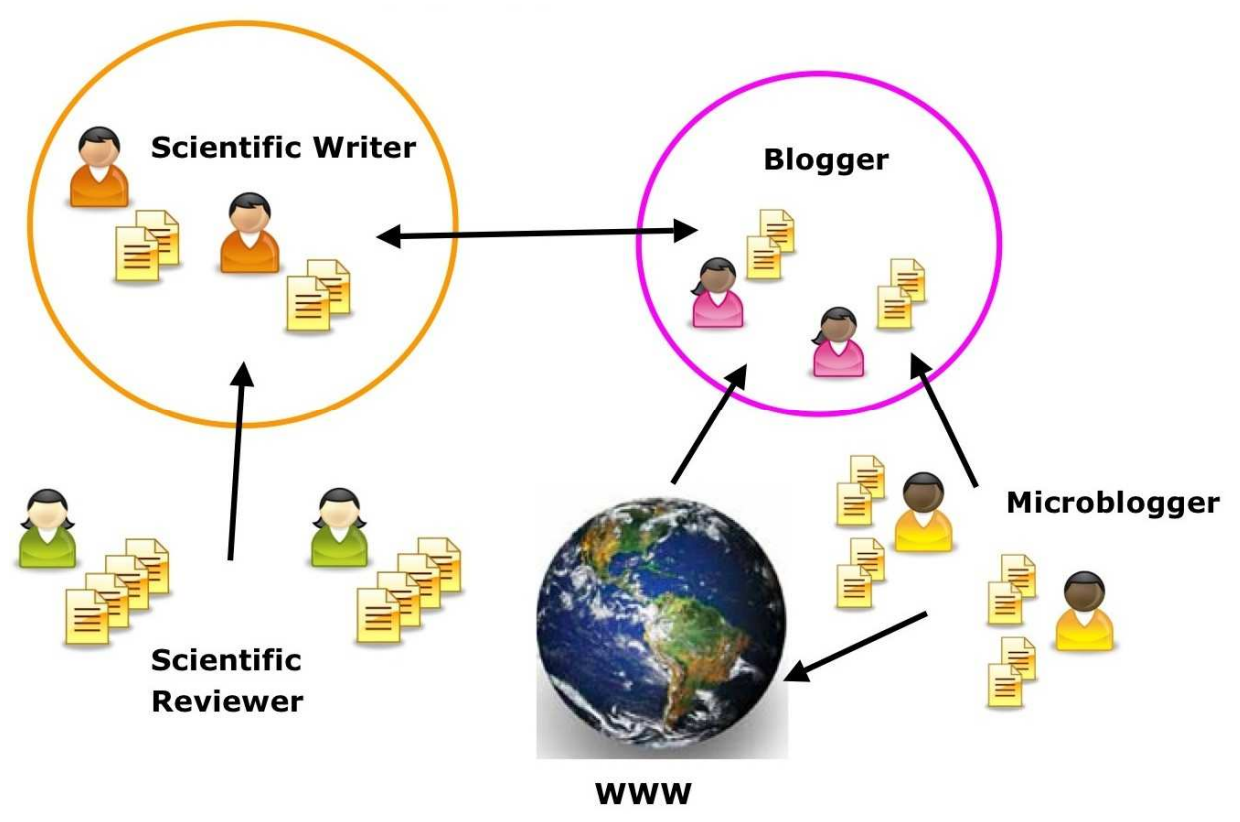

Figure 1 shows an overview of the concept. On the one side two writing groups (Scientific Writer and Blogger) and on the other side two reviewing groups (Scientific Reviewer and Microblogger) should help to ensure the quality aspect. Each URL or reference is verified as well as assumptions made within a document or a post. Learners are also strongly encouraged and motivated to write about their opinion instead of copying the expert's thoughts. Of course this kind of personal refection should lead to a deep discussion between writer and reviewers, which is intended and claimed by the lecturers.

Furthermore two different channels are used to research the differences between two different kind of writings - traditional writing versus blogging:

1. The journey is the reward: One of the big disadvantages of the learn methods, accomplished in preceding years was that learners wrote their essays only immediately before the deadlines. Discussions did not occur due to the fact that students did not follow the content of the lecture just in time. With the help of weblogs and the requirement to provide at least 2 posts each semester week it is ensured that learners bear the content in mind during the whole semester. Microbloggers bring also new stuff to the blogging community by commenting and posting short microblogs.

2. Digital content: One of the major problems of text documents is that it is restricted to the static content, like text or photos. It is hard to provide interactive content like videos, animations, 
learning objects and so on. With the help of weblogs it becomes easy to provide, reflect and discuss that kind of contents.

3. Community / Networking: A blogging student has to write his contributions to a so called community weblog about his/her chosen topic. Of course every learner can observe what his/her colleagues are writing and discussing. From a research point of view this might lead to an implicit information exchange - students never read long essays from other students, but maybe look at short contributions, videos, bookmarks if they are placed immediately to their working environment. Furthermore this kind of weblog should also help the learners feel that they are part of the writing community instead of "writing to pass the lecture".

\section{Technical Concept}

Graz University of Technology has been offering an own learning management system (TeachCenter) and an own blogosphere (LearnLand) since October 2006.

The learning management system bases on the current developments of the Institute for Information Systems and Computer Media called WBT-Master. The idea behind it is to offer each lecture course a virtual course enhanced by all communication and e-Learning possibilities [28]. With other words the lecture "Social Aspects of Information Technologies" has been implemented within the system and offers students a virtual board, an overview about all administrative activities and all relevant materials to the course as well as further features for uploading essays and reviews or discussion forum. The learning management system must be seen as the centre of all activities. Figure 2 shows the main course page - in the middle lecture notes for each presentation are available, on the right sidebar a widget displays all microblog postings (green), an additional feature allows the upload of articles for Scientific Writer and Reviewer (blue) and with the aid of RSS Feeds all contributions of Community Weblogs can be shown within the course (red).

Figure 2. TeachCenter - the centre of all activities.

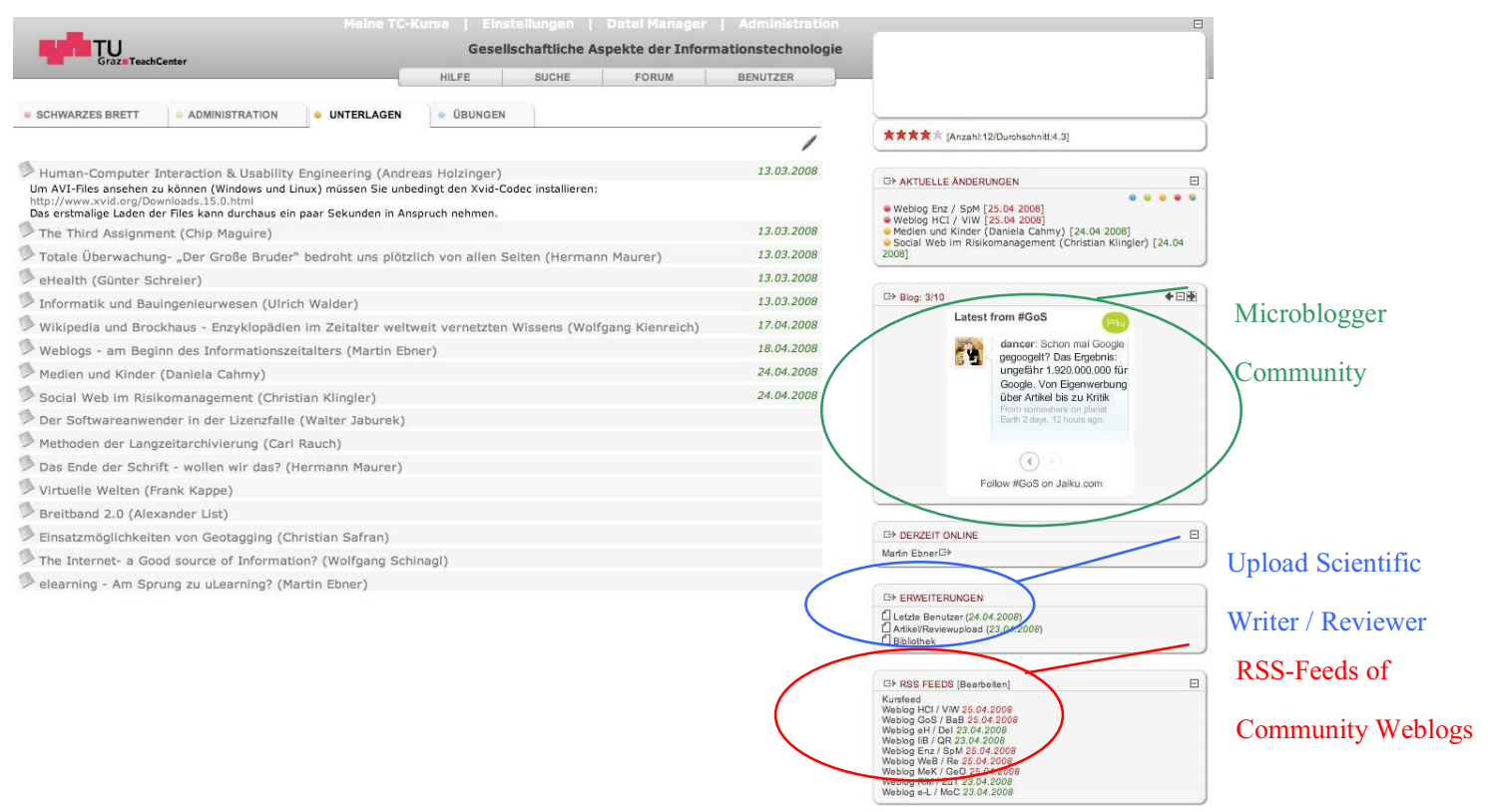


The community Weblogs are offered via LearnLand, which bases on the open-source software ELGG (http://elgg.org). Each university member (lecturer/student) is able to create his/her own weblog. Furthermore community weblogs are provided for a specific topic or lecture. There is a difference between a personal weblog and a community weblog. Writing within a community weblog is allowed only to its members. In other words each member of the blogosphere owns his/her personal weblogs and is a member of additional arbitrarily community weblogs. For this lecture nine Community Weblogs have been created. Figure 3 shows the Community Weblog on the topic "Media \& Children". The latest contribution is placed on the top. On the right side active users, saved bookmarks, an overview of members and search possibilities are offered.

Due to the fact that channels can be created simply and the mobile client was very convincing the platform for microblogging Jaiku was chosen. Furthermore by the possibility to embed RSS feeds of external resources the Community Weblog is observable. With the help of widgets the last microblogposts are immediately visible in the Community Weblogs as well as in the learning management system (for example, see Figure 2).

Figure 3. Community Weblog Media \& Children.

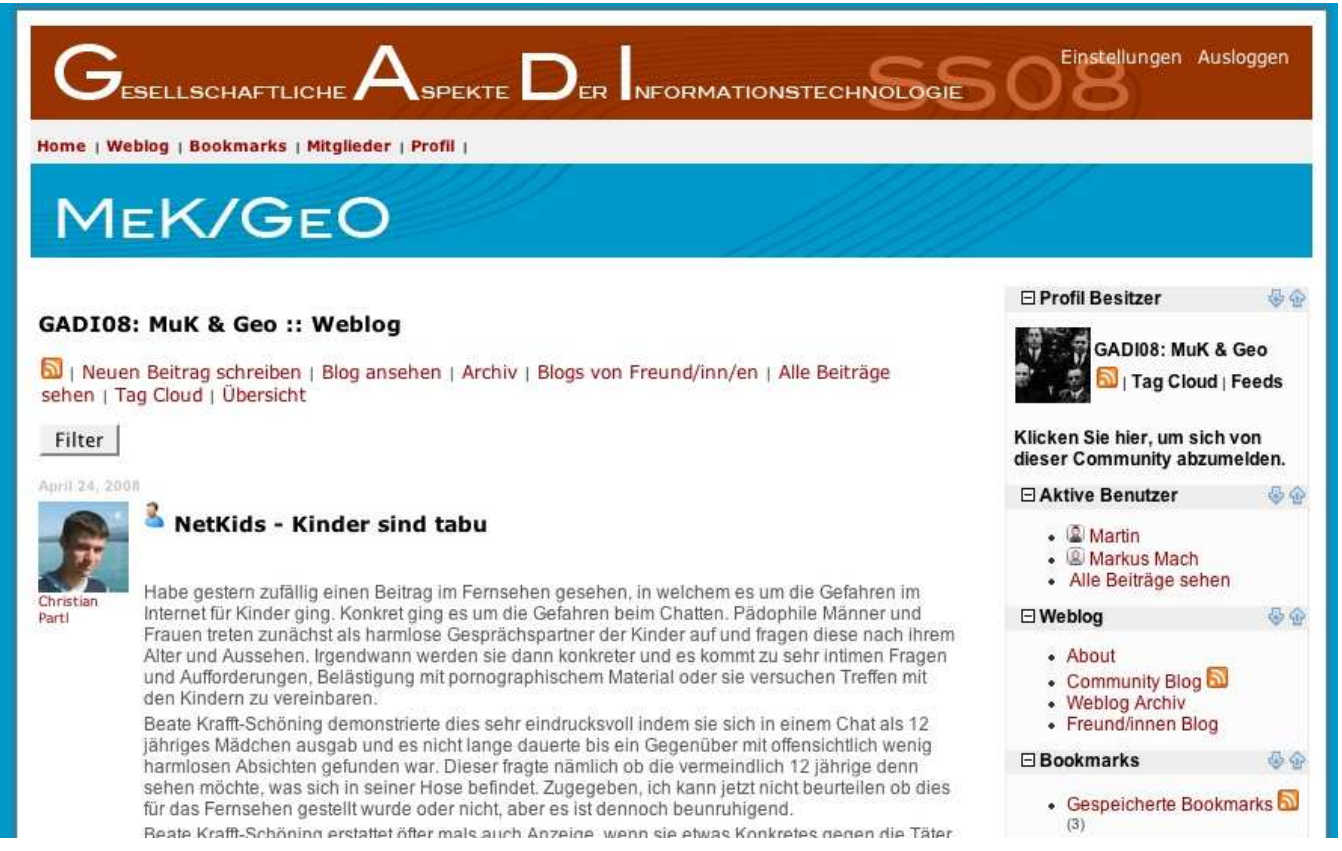

\section{Evaluation Results - The point of view of the students}

In the end of the lecture an online questionnaire took place to gain user experiences about their feelings, likes and dislikes about the whole concept. 149 of $185(81 \%)$ lecture participants filled out the questions and helped to become the evaluation valuable. Some important research questions are point out below:

Research Question 1: Before the start of the lecture I

- did not know about Microblogging (1).

- have already heard about Microblogging (2). 
- have already used Microblogging for at least once (3).

- have already been an active Microblogger (4).

Table 1. Pre-knowledge about Microblogging.

\begin{tabular}{|l|l|l|l|l|}
\hline & 1 & 2 & 3 & 4 \\
\hline Students & 128 & 17 & 2 & 2 \\
\hline
\end{tabular}

Table 1 and Research Question 1 point out that nearly nobody of the students ever heard about microblogging or used such a tool before. Due to this fact the use of such a tool seems to be a very innovative approach.

Research Question 2: Have you ever read your reviews you got from your colleagues?

Table 2. Observation of Reviews.

\begin{tabular}{|l|l|l|}
\hline & Yes & No \\
\hline Scientific Writer & $79 \%$ & $21 \%$ \\
\hline Blogger & $49 \%$ & $51 \%$ \\
\hline
\end{tabular}

Table 2 shows the answer of the students if they have followed the reviews to their articles (Scientific Writer) or Weblog contributions (Blogger). Due to the fact that reading of these essays was on voluntary bases it shows that learners were interested in how other thinking about their meanings and opinions. Bloggers care about the comments arbitrarily less compared with the Scientific Writer. Although Weblogs are a kind of communication this did not really happen, maybe a fact of the learning behavior - Learners are doing mainly what teachers want to.

Research Question 3: What do you think about the use of Microblogging in Higher Education?

This Question should point out how students think about the potentials, advantages as well as disadvantages by the use of this possibility. Are there useful scenarios, examples or is it only a big hype?

The following statements show the opinions of the learners:

- It is maybe useful for a kind of virtual announcements - lecture schedules as well as sharing different resources can be posted via the microblog stream

- Exchange of information - microblogs can work as enhancement of traditional newsgroups

- Microblogs can be used for fast discussion about several topics or even lectures

- Microblogs help to share links and short ideas

- Microblogs are useful to give a hint to a Weblog contribution

- It is a new and different way for discussions and it needs some times to realize how microblogs are working. Newsgroups are much more comfortable 
- Problems of Microblogs are that the contributions are public.

- Microblogging is a quick possibility to share thoughts and discuss with different people

- Microblogging is interesting and should be combined with existing communication infrastructure (newsgroups, discussion forums ..)

- Microblogging leads to a new kind of information flow - nice add on

- Interesting for groups who are working on the same topic over a long time period

- Microblogging is a more interactive media between people of same interests

\section{Discussion}

We want to summarize here whether weblogs and microblogs helped to fulfill the three crucial factors as defined within the didactical approach as confirmed by the evaluation results as well as the feedback of lecturers and students.

1. Reflection: Due to the per-review concept the traditional writing groups and the bloggers provided much more personal statements than in years before. Independent of the technology used it can be pointed out that this methodology is definitely an appropriate possibility to allow more critical and personal statements.

2. Moreover, it must be pointed out that especially the Blogger group unknowingly wrote more and more personal notes. After a first phase of providing links, pictures or videos it seems that even the WorldWideWeb is an endless resource because students turned more and more to personal statements and experiences due to the fact that the Internet provides no new stuff. Bloggers as well as microbloggers become over time more and more reflective.

3. Discussion: Reviews as an element to start discussions did not work within this course. Concerning the didactical concept the lecturers hoped that students of the Scientific Writer group begin to comment the reviews they get. In the Weblog - Microblog setting some discussions about particularly provoking contributions appeared. This effect can be substantiated through the fact that commenting is easier, faster and requires much smaller statements. In former years similar experiments have been done where students were forced to do comments to other students contributions - but going through such discussions in the end of the course pointed out that the comments were as short as possible and boring. Mandatory discussion contributions lead to no increasing lecture outcome.

4. Quality: In all groups the quality increases considerably in comparison to preceding years. Not only because of an automatically plagiarism check, but also because of the knowledge that the articles and contributions will be reviewed and commented.

\section{Conclusion}

Weblogs and microblogs can enhance lectures by bringing the resources of the WorldWideWeb to the course and making them discussable. Both new technologies, however, cannot replace writing essays and articles, because of their different nature. But the transfer of thoughts and short statements 
is much more appropriate using this kind of media. Critical thinking and quality assurance need control elements: the microblogging group was essential for doing this by using comments of bloggers' contributions.

In the end it has to be said that the most positive effect of weblogs usage was that the students wrote about a topic over a longer period of time. This led to a more in depth cognitive process: each blogger discussed his topic much more in detail than a comparable Scientific Writer. Thus it can be stated that weblogs as well as microblogs are very good for reflections over a longer time period, involving more exploring and discussing. How weblogs can support informal learning and community building will be investigated in much more detail in our future research.

\section{Acknowledgements}

We would like to express our gratitude to Behnam Taraghi, student of telematics at Graz University of Technology, for supporting this study by administrating the TU Graz LearnLand. We thank also the whole team of Institute for Information Systems and Computer Media, the team of Social Learning and the team of computing department for their endless patience during the installation and implementation process. Finally, we would like to express our gratitude to all students participating in this project and providing the necessary content.

\section{References and Notes}

1. Prensky, M. Digital natives, Digital immigrants. On the Horizon 2001, 9, 1-6.

2. Maurer, H.; Schinagl, W. Wikis and other e-Communities are changing the Web. In Proceedings of the World Conference on Educational Multimedia, Hypermedia \& Telecommunications (EDMEDIA 2006); AACE: Chesapeake, VA, USA, 2006; pp. 2858-2866.

3. Korica, P.; Maurer, H.; Schinagl, W. The growing importance of e-Communites on the Web. In Proceedings of the International Conference on Web Based Communities 2006; IADIS, San Sebastian, Spain, February 2006; pp. 165-174.

4. Ziefle, M. The influence of user expertise and phone complexity on performance, ease of use and learn ability of different mobile phones. Behav. Inform. Technol. 2002, 21, 303-311.

5. Holzinger, A.; Nischelwitzer, A.; Meisenberger, M. Mobile Phones as a Challenge for mLearning: Examples for Mobile Interactive Learning Objects (MILOs). In Proceedings of the IEEE International Conference on Pervasive Computing and Communications (PerCom 2005), Kauai Island, HI, USA, March 2005; Tavangarian, D., Ed.; IEEE: Los Alamitos, CA, USA, 2005; pp. 307-311.

6. Holzinger, A.; Nischelwitzer, A.; Meisenberger, M. Lifelong-Learning Support by M-learning: Example Scenarios. eLearn 2005, 2005, Article 5.

7. Ally, M. Mobile Learning. IRRODL 2007, 8 (Guest Editorial).

8. Oblinger, D.D., Oblinger, J.L., Eds. Educating the Net Generation; Educause: Boulder, CO, USA, 2005. Available online at: http://www.educause.edu/educatingthenetgen.

9. Schulmeister, R. Gibt es eine Net-Generation? Whitepaper, 2008 (in German). Available online at: http://www.izhd.uni-hamburg.de/pdfs/Schulmeister_Netzgeneration.pdf. 
10. Bullen, M.; Morgan, T.; Belfer, K.; Qayyum, A. . The Net Generation in Higher Education: Rhetoric and Reality. Int. J. of Excellence in E-Learning 2009, 2, p. 1-13

11. O'Reilly, T. What is Web 2.0? - Design Patterns and Business Models for the Next Generation Software. Whitepaper, 2005. Available online at: http://www.oreilly.com/pub/a/oreilly/tim/news/2005/09/30/what-is-web-20.html.

12. Downes, S. E-learning 2.0. eLearn 2005, 2005, Article 10.

13. Schmid, J.; Schönberger, C.; Stegbauer, C. Erkundungen von Weblog-Nutzungen - Anmerkungen zum Stand der Forschung. kummunikation@gesellschaft 2005, 6, 1-20 (in German).

14. Walker, J. Weblog. Routledge Encyclopedia of Narrative Theory, 2003. Available online at: http://jilltxt.net/archives/blog_theorising/final_version_of_weblog_definition.html.

15. Rosenbloom, A. The blogosphere. Commun. ACM 2004, 47, 31-33.

16. Farmer, J.; Bartlett-Bragg, A. Blogs@ anywhere: High fidelity online communication. In Proceedings of the ASCILITE 2005 Conference: Balance, Fidelity, Mobility: maintaining the momentum?, Brisbane, Australia, 2005; pp. 197-203.

17. Kolbitsch, J. Kōrero: An Integrated, Community-Based Platform for Collaboration. In Proceedings of the International Conference on Knowledge Management (ICMK'07), Vienna, Austria, 27-28 August, 2007; pp. 1-13.

18. Karger, D.R.; Quan, D. What would it mean to blog on the semantic Web? J. Web Semantics 2005, 3, 147-157.

19. Porter, L.V.; Sweetser Trammell, K.D.; Chung, D.; Kim, E. Blog Power: Examining the effects of practitioner blog use on power in public relations. Public Relat. Rev. 2007, 33, 92-95.

20. Heise.de. Studie: Blogger sind "investigative Multiplikatoren". Whitepaper, 2007 (in German). Available online at: http://www.heise.de/newsticker/meldung/85081/from/rss09.

21. Luca, J.; McLoughlin, C. Can blogs promote fair and equitable teamwork? In Proceedings of ASCILITE 2005 Conference: Balance, Fidelity, Mobility: maintaining the momentum?, Brisbane, Australia, 2005; pp. 379-385.

22. Peschke, R.; Lübecke, M. Zukunft Weblog?! - Lesen, Schreiben und die Materialität der Kommunikation. Anmerkungen $\mathrm{zu}$ einem neuen Typus der Online Kommunikation aus kommunikationstheoretischer Sicht. kommunikation@gesellschaft 2005, 7, 1-27 (in German).

23. McFedries, P. All A-Twitter. IEEE Spectrum 2007, 84. Available online at: http://www.spectrum.ieee.org/computing/software/all-atwitter.

24. Java, A.; Finin, T.; Song, X.; Tseng, B. Why We Twitter: Understanding Microblogging Usage and Communities. Paper presented at the joint 9th WEBKDD and 1st SNA-KDD Workshop, New York, NY, USA, 2007.

25. Ebner, M; Schiefner, M. Microblogging - more than fun? In Proceedings of the IADIS Mobile Learning Conference 2008, Algarve, Portugal, April 2008; Sánchez, I.A., Isaías, P., Eds., 2008; pp. 155-159.

26. Dewey, J. Democracy and Education. An introduction to the philosophy of education, 1916; reprinted by Free Press: Rockland, NY, USA, 1997. 
27. Ebner, M.; Holzinger, A.; Maurer, H. Web 2.0 Technology: Future Interfaces for Technology Enhanced Learning? In Universal Access in Human-Computer Interaction - Application and Services, 4th International Conference in Human Computer Interaction, Beijing, China, 2007; Stephanidis, C., Ed.; Springer: Berlin, Germany, 2007; pp.559-568.

28. Maurer, H. HyperWave: The Next Generation Web Solution. Addison-Wesley Longman: London, UK, 1996.

(C) 2009 by the authors; licensee Molecular Diversity Preservation International, Basel, Switzerland. This article is an open-access article distributed under the terms and conditions of the Creative Commons Attribution license (http://creativecommons.org/licenses/by/3.0/). 